\title{
Longitudinal CSF biomarkers in patients with early Parkinson disease and healthy controls OPEN
}

Brit Mollenhauer, MD

Chelsea J. Caspell-Garcia, MS

Christopher S. Coffey, $\mathrm{PhD}$

Peggy Taylor, ScD Leslie M. Shaw, PhD John Q. Trojanowski, $\mathrm{MD}, \mathrm{PhD}$

Andy Singleton, $\mathrm{PhD}$

Mark Frasier, PhD

Kenneth Marek, MD

Douglas Galasko, MD

For the Parkinson's

Progression Marker Initiative

Correspondence to Dr. Mollenhauer: brit.mollenhauer@med.unigoettingen.de

Supplemental data at Neurology.org

\section{ABSTRACT}

Objective: To analyze longitudinal levels of CSF biomarkers in drug-naive patients with Parkinson disease (PD) and healthy controls (HC), examine the extent to which these biomarker changes relate to clinical measures of $P D$, and identify what may influence them.

Methods: CSF $\alpha$-synuclein ( $\alpha$-syn), total and phosphorylated tau (t- and $p$-tau), and $\beta$-amyloid 1$42(\mathrm{~A} \beta 42)$ were measured at baseline and 6 and 12 months in 173 patients with PD and 112 matched $\mathrm{HC}$ in the international multicenter Parkinson's Progression Marker Initiative. Baseline clinical and demographic variables, PD medications, neuroimaging, and genetic variables were evaluated as potential predictors of CSF biomarker changes.

Results: CSF biomarkers were stable over 6 and 12 months, and there was a small but significant increase in CSF A 42 in both patients with patients with PD and HC from baseline to 12 months. The t-tau remained stable. The $p$-tau increased marginally more in patients with PD than in HC. $\alpha$-syn remained relatively stable in patients with $\mathrm{PD}$ and $\mathrm{HC}$. Ratios of $\mathrm{p}$-tau/t-tau increased, while t-tau/ A 42 decreased over 12 months in patients with PD. CSF biomarker changes did not correlate with changes in Movement Disorder Society-sponsored revision of the Unified Parkinson's Disease Rating Scale motor scores or dopamine imaging. CSF $\alpha$-syn levels at 12 months were lower in patients with PD treated with dopamine replacement therapy, especially dopamine agonists.

Conclusions: These core CSF biomarkers remained stable over 6 and 12 months in patients with early PD and HC. PD medication use may influence CSF $\alpha$-syn. Novel biomarkers are needed to better profile progressive neurodegeneration in PD. Neurology ${ }^{\circledR}$ 2017;89:1959-1969

\section{GLOSSARY}

$\boldsymbol{\alpha}$-syn $=\alpha$-synuclein; $\mathbf{A} \boldsymbol{\beta} 42$ = $\beta$-amyloid 1-42; $\mathbf{A D}=$ Alzheimer disease; $\mathbf{H C}=$ healthy controls; $\mathbf{L E D}=$ levodopa equivalent dose; MDS-UPDRS = Movement Disorder Society-sponsored revision of the Unified Parkinson's Disease Rating Scale; MoCA = Montreal Cognitive Assessment; $\mathbf{p}$-tau = phosphorylated tau protein; PD = Parkinson disease; Penn = University of Pennsylvania; PPMI = Parkinson's Progression Biomarker Initiative; RBD = REM sleep behavior disorder; RBD-SQ = REM sleep behavior disorder screening questionnaire; $\mathbf{t}$-tau $=$ total tau protein

Intracellular accumulation of $\alpha$-synuclein ( $\alpha$-syn) aggregates, neuronal dysfunction and loss, and synaptic changes are the neuropathologic hallmarks of Parkinson disease (PD). Mutations and duplications in the $\alpha$-syn encoding gene (SNCA) are associated with autosomal dominantly inherited PD, providing further support for a central role of $\alpha$-syn in PD. ${ }^{1}$ Recent evidence suggests that transcellular spread of aggregated or misfolded $\alpha$-syn may contribute to progression ${ }^{2}$ via the extracellular space. This raises the possibility that the quantification of $\alpha$-syn in extracellular fluids may be a marker for PD diagnosis and progression. Total tau ( $\mathrm{t}$-tau) and phosphorylated tau ( $\mathrm{p}$-tau)

From the Department of Neurology (B.M.), University Medical Center, Göttingen; Paracelsus-Elena-Klinik (B.M.), Kassel, Germany; Department of Biostatistics (C.J.C.-G., C.S.C.), College of Public Health, University of Iowa, Iowa City; BioLegend Inc. (P.T.), San Diego, CA; Department of Pathology \& Laboratory Medicine (L.M.S., J.Q.T.), Center for Neurodegenerative Disease Research, Institute on Aging (L.M.S. , J.Q.T.), and Morris K. Udall Center of Excellence for Parkinson's Disease Research (J.Q.T.), Perelman School of Medicine, University of Pennsylvania, Philadelphia; Molecular Genetics Section (A.S.), Laboratory of Neurogenetics, National Institute on Aging, NIH, Bethesda, MD; The Michael J. Fox Foundation for Parkinson's Research (M.F.), New York, NY; Institute for Neurodegenerative Disorders (K.M.), New Haven, CT; and Department of Neurosciences (D.G.), University of California, San Diego.

Coinvestigators are listed at Neurology.org.

Go to Neurology.org for full disclosures. Funding information and disclosures deemed relevant by the authors, if any, are provided at the end of the article. The Article Processing Charge was funded by The Michael J. Fox Foundation for Parkinson's Research.

This is an open access article distributed under the terms of the Creative Commons Attribution-NonCommercial-NoDerivatives License 4.0 (CC BY-NC-ND), which permits downloading and sharing the work provided it is properly cited. The work cannot be changed in any way or used commercially without permission from the journal. 
protein, as well as $\beta$-amyloid 1-42 (A $\beta 42)$, correlate with key pathologic features in Alzheimer disease (AD). ${ }^{3,4}$ These proteins have been shown to be relevant in PD neurodegeneration with an association between the microtubule-associated protein tau (MAPT) gene with PD and a known overlapping pathology (with $\mathrm{AD}$ ). In crosssectional studies, levels of $\alpha$-syn in CSF are decreased in PD and related disorders. ${ }^{5-7}$ This decrease of CSF $\alpha$-syn and changes in t-tau and p-tau protein and $A \beta 42$ was recently replicated in the large multicenter Parkinson's Progression Biomarker Initiative (PPMI). ${ }^{8,9}$ Longitudinal changes in levels of CSF $\alpha$-syn and other biomarkers in PD were examined in other cohorts, ${ }^{10-14}$ with suggestions that CSF $\alpha$-syn may increase over time or in those with more severe PD. Understanding the dynamics of changes in biomarkers may advance our understanding of the pathobiology of the disease course, identify contributions of different pathologies to progression, ${ }^{15,16}$ and can provide benchmark data for the design and interpretation of disease-modifying clinical trials that use biomarkers for participant enrollment or as outcome measures.

We therefore analyzed the levels of $\alpha$-syn, tau, p-tau, and A 342 in CSF samples of patients with PD and healthy controls (HC) at baseline and 6- and 12-month follow-up in the PPMI cohort. We hypothesized that these core CSF biomarkers would be stable in patients with $\mathrm{PD}$ and HC and would correlate with clinical or ${ }^{123}$ I-ioflupane dopamine transporter imaging (DaTscan) indices of disease progression.

METHODS Participants. People with recently diagnosed untreated PD were enrolled in PPMI. PPMI is an ongoing prospective longitudinal, observational, international multicenter study that aims to identify biomarkers for the progression of PD. As described previously, ${ }^{9}$ newly diagnosed, drug-naive patients with PD ( $\mathrm{n}=423)$, age- and sex-matched HC $(\mathrm{n}=196)$, and participants with scans without evidence of dopaminergic deficit syndrome $(n=60)$ were included in the study. Recruitment took place between June 2010 and May 2013, in 21 PD centers in the United States and Europe in accordance with PPMI protocols (ppmi-info.org/study-design). ${ }^{17}$ The criteria for enrollment between June 2010 and May 2013 for participants with PD were (1) age over 30 years; (2) presence of 2 of the following: bradykinesia, rigidity, and resting tremor, or presence of an asymmetric resting tremor, or asymmetric bradykinesia; (3) diagnosis recently made within the last 24 months; (4) PD drug naivety; and (5) dopamine transporter deficit in the putamen on the DaTscan by central reading. This article is based on the data from CSF samples obtained at baseline and 6- and 12-month follow-up visits and analyzed for t-tau and $p$-tau, $A \beta 42$, and $\alpha$-syn. Our findings reflect data collected as of January 19, 2016, from the PPMI database (ppmi-info.org).

Standard protocol approvals, registrations, and patient consents. Approval was received from the ethical standards committee on human experimentation for all experiments with human participants. Written informed consent was obtained from all study participants (consent for research). The study is registered in clinicaltrials.gov as NCT01141023.

CSF sample collection and analysis. CSF was collected using standardized lumbar puncture procedures. Sample handling, shipment, and storage were carried out as described in our previous study ${ }^{8}$ and the PPMI biologics manual (ppmi-info.org). Aliquots of $0.5 \mathrm{~mL}$ frozen CSF were shipped from the PPMI Biorepository Core laboratories to the University of Pennsylvania (Penn) PPMI Biomarker Core and to BioLegend (San Diego, CA) for analyses. Measurements of CSF A $\beta 42$, tau, and p-tau were made using the xMAP-Luminex platform with INNOBIA AlzBio3 immunoassay kit-based reagents (Fujirebio-Innogenetics, Ghent, Belgium) at Penn, as we have described elsewhere. ${ }^{8}$ Commercially available sandwich type immunoassay kits (BioLegend; formerly Covance) were used to analyze CSF $\alpha$-syn and CSF hemoglobin levels, as described previously. ${ }^{8}$

Clinical assessment measures. The clinical assessment battery is described on the PPMI website. In brief, motor assessment was performed with the Movement Disorder Society-sponsored revision of the Unified Parkinson's Disease Rating Scale (MDSUPDRS $)^{18}$ III and total score. At baseline, all participants with PD were free of dopamine-related medications. Use of medications for PD was recorded at the 6-and 12-month visits, and is expressed as levodopa equivalent doses (LEDs). ${ }^{19}$

Cognitive testing comprised screening with the Montreal Cognitive Assessment (MoCA) and the Hopkins Verbal Learning Test-revised, processing speed/attention was assessed using the Symbol Digit Modality Test, executive function/working memory was assessed with the Wechsler Memory Scale III LetterNumber Sequencing Test, and visuospatial abilities were assessed with the Benton Judgment of Line Orientation test. The REM sleep behavior disorder (RBD) screening questionnaire (RBD-SQ) was used to assess RBD. ${ }^{20}$

Dopamine SPECT imaging. Dopamine imaging was performed by DaTscan using standardized methods, as described. ${ }^{17}$ We analyzed whether quantitative DaTscan measures of caudate, putamen, or striatal uptake were related to CSF biomarker changes.

Genetic variables. To examine whether selected genetic variants were associated with CSF biomarkers, we used data for $A P O E$ genotypes and single nucleotide polymorphisms related to SNCA. These were measured by the PPMI Genetics Core as previously described. ${ }^{17,21}$

Statistical analysis. All analyses are based on data retrieved from the PPMI website, when all biomarkers for the 6- and 12-month follow-up periods were available on January 19, 2016. All statistical analyses were performed using SAS 9.4 (SAS Institute Inc., Cary, NC). All tests performed using the CSF biomarkers were rank-based. $t$ Tests or $\chi^{2}$ were used to compare baseline demographic and clinical variables in participants with longitudinal CSF data vs participants who only had baseline CSF data; these comparisons were performed separately in patients with PD and controls. Nonparametric tests were used where specified in the tables. Repeated-measures linear mixed models were used to test for changes in CSF biomarker levels from 
Table 1 Baseline clinical characteristics of patients with Parkinson disease (PD) and healthy controls $(\mathrm{HC})$ with longitudinal CSF data

Patients with PD ( $\mathrm{n}=173)$

$\mathrm{HC}(\mathrm{n}=112)$

Age at baseline lumbar puncture, y

$$
\text { n }
$$

Mean (SD)

173

60.91 (9.3)

$95 \% \mathrm{Cl}$

Sex, n (\%)

Men

Women

Age at PD onset, y

n

Mean (SD)

$95 \% \mathrm{Cl}$

MDS-UPDRS part III (motor) score

n

Mean (SD)

$95 \% \mathrm{Cl}$

MDS-UPDRS total score

n

Mean (SD)

$95 \% \mathrm{Cl}$

TD/non-TD classification, $\mathrm{n}(\%)$

TD

Non-TD

HVLT total recall

n

Mean (SD)

$95 \% \mathrm{Cl}$

HVLT delayed recall

n

Mean (SD)

$95 \% \mathrm{Cl}$

HVLT discrimination recognition

n

Mean (SD)

$95 \% \mathrm{Cl}$

MoCA

n

Mean (SD)

95\% Cl

SDMT

n

Mean (SD)

95\% Cl

LNS

n
59.5-62.3

124 (72)

49 (28)

70 (63)

42 (38)

169

$58.79(9.7)$

173

21.86 (8.6)

20.6-23.2

173

33.61 (13.4)

31.6-35.6

126 (73)

47 (27)

173

24.43 (4.5)

23.8-25.1

173

8.29 (2.4)

7.9-8.7

173

9.62 (2.5)

9.3-10.0

173

27.04 (2.2)

26.7-27.4

173

112

41.43 (8.8)

40.1-42.8

173

112
57.3-60.3 baseline to 6 and 12 months. In cases where the change in CSF biomarker levels was significant at the 0.1 level, simple linear models were used to analyze potential baseline predictors of change. First, the univariate relationship between each predictor and the biomarker change was examined. Then, any variables that had univariate associations with $p$ values less than 0.2 were included in a multivariable model. Finally, a backwards selection process was used to remove variables individually until all variables remaining in the model were significant at the 0.01 level.

Repeated-measures linear mixed models were also used to test for overall differences in CSF levels, MDS-UPDRS, and DaTscan levels between groups over time. In each of these models, an interaction between time and group was tested first, before testing for an overall group difference. Tests of interactions were reported where $p$ values were significant at the 0.1 level. If the test of interaction was not significant, the interaction term was removed from the model and a test for overall group difference was reported.

Spearman rank correlation coefficients between changes in CSF biomarker levels and changes in MDS-UPDRS scores and DaTscan variables were also reported. In addition, repeated-measures linear mixed models were used to examine longitudinal relationships between CSF biomarker levels and DaTscan levels and PD medication use.

Unless otherwise specified, a significance level of $p=0.01$ was used as the cutoff to account for multiple comparisons. A more formal method of adjustment for multiple comparisons was not used, as the authors believed this would have been too stringent given the exploratory nature of these analyses.

RESULTS Demographic and clinical data of the 173 patients and 112 controls are shown in table 1 . The flow of participants is shown in figure e-1 at Neurology.org and associated genetic and imaging data in these cohorts in table e-1. Comparisons between this longitudinal CSF cohort and the remaining 239 PPMI patients and 77 controls (with baseline CSF data only) revealed small differences in sex (more men were in the longitudinal CSF data group; $p=0.03$ ). Also, baseline CSF A 342 and $p$-tau values were slightly lower in the longitudinal cohort compared to those with only baseline data available ( $p=0.05$ and 0.01 , respectively) (table e-2).

Changes in CSF biomarkers in patients with PD and controls over time are shown in table 2. Levels of $A \beta 42$ increased slightly in patients with PD and $\mathrm{HC}$, which was significant from baseline to 12 months. While t-tau remained relatively stable over time in both groups, ptau significantly increased in patients with PD (baseline vs 12 months) but not in controls (table 2). The ratio of $\mathrm{p}$-tau to t-tau increased between baseline and 12 months and the ratio of $t$-tau to $A \beta 42$ declined slightly over time in the patients with PD only. CSF total $\alpha$-syn levels remained relatively stable, as did the ratio of $\mathrm{t}$-tau to $\alpha$-syn from baseline to 12 months (table 2).

Comparing changes in CSF biomarkers over time in the PD group with those in controls, we found that $\mathrm{t}$-tau, $\mathrm{p}$-tau, and $\alpha$-syn levels in patients with PD were significantly lower than in $\mathrm{HC}$ across time points. When samples with hemoglobin in CSF $>200 \mathrm{ng} / \mathrm{mL}$ were excluded $(\mathrm{PD} \mathrm{n}=91$ and $\mathrm{HC}$ $\mathrm{n}=69)$ the comparison of patients with PD vs HC 


\begin{tabular}{|c|c|c|c|}
\hline Table 1 & Continued & & \\
\hline & & Patients with PD $(n=173)$ & $\mathrm{HC}(n=112)$ \\
\hline Mean (SD) & & 10.84 (2.3) & $10.86(2.6)$ \\
\hline $95 \% \mathrm{Cl}$ & & $10.5-11.2$ & $10.4-11.3$ \\
\hline \multicolumn{4}{|l|}{ BJLO } \\
\hline $\mathrm{n}$ & & 173 & 112 \\
\hline Mean (SD) & & $12.94(2.1)$ & $13.21(1.9)$ \\
\hline $95 \% \mathrm{Cl}$ & & $12.6-13.3$ & 12.9-13.6 \\
\hline
\end{tabular}

Abbreviations: BJLO = Benton Judgment of Line Orientation test; $\mathrm{Cl}=$ confidence interval; HVLT $=$ Hopkins Verbal Learning Test; LNS = Letter-Number Sequencing Test; MDSUPDRS = Movement Disorder Society-sponsored revision of the Unified Parkinson's Disease Rating Scale; MoCA = Montreal Cognitive Assessment; NA = not applicable; SDMT = Symbol Digit Modality Test; TD = tremor dominant.

became nonsignificant, probably due to fewer participants (table 3).

In multivariate regression analysis that examined baseline predictors of changes in biomarkers, we found that no cognitive test was a significant predictor of changes in levels of CSF biomarkers. Similarly, cognitive dysfunction $(\mathrm{MoCA}<26)$, the presence of hallucinations (MDS-UPDRS I. $2 \geq 1$ ), and the presence of RBD (RBD-SQ $\geq 5$ ) in the patients with PD at baseline were not significant predictors of any of the CSF biomarkers. A limited number of genetic variants were examined as predictors, including $A P O E \& 4$ and polymorphisms in the SNCA gene. Among these, the genetic polymorphism at $S N C A$ rs3910105 was a significant predictor for the change in $A \beta 42$. The increase of $p$-tau and the ratios $p$-tau/ $\mathrm{t}$-tau and $\mathrm{p}$-tau/A 342 were significantly predicted by sex (men having a more pronounced increase) and by the polymorphism of $S N C A$ rs 356181 . The decrease of $\mathrm{t}$-tau/A 42 was significantly predicted by the polymorphism of SNCA rs3910105 (data not shown). Table e-3 shows predictors of significant changes in $\mathrm{A} \beta 42$ and $\mathrm{p}$-tau from baseline to 12 months in patients with PD.

We also examined correlations between changes in CSF biomarkers and key clinical measures (MDS-UPDRS part III score and total score), each of which increased over 6 and 12 months in PD (tables 4 and 5). However, after adjustment for multiple comparisons, no significant correlations were observed.

We analyzed whether the use and LED of PD medications during the 12 months follow-up period were associated with changes in CSF biomarkers (table 5). We found that patients using PD medications had greater decreases in $\alpha$-syn than those who did not take medications. This was driven by the subgroup who used dopamine agonists, not other dopamine replacement (tables e- 4 and e-5), and there was only a weak relationship with LED. There was no relationship with changes in other CSF biomarkers.
There were moderate and significant correlations among the 4 CSF markers, which are summarized in table e-6.

DISCUSSION This multicenter longitudinal study evaluated core CSF biomarkers-including $\alpha$-syn, $\mathrm{A} \beta 42$, t-tau, and p-tau levels-measured over 6 and 12 months in patients with de novo PD and healthy controls. The strengths of the data include quality control and standardization of recruitment of participants, support of clinical diagnosis through DaTscan imaging, rigorous clinical assessment, CSF and biosample collection, handling and central analysis according to established standardized operational procedures, and functional as well as structural brain image analysis, together with high recruitment numbers, retention rates, and rates of performance of longitudinal lumbar punctures. The diversity of enrollment sites is representative of a typical multicenter interventional study. Therefore, these data can serve as a benchmark for future intervention trials.

Overall, we show stability of all 4 biomarkers during 12 months of follow-up in de novo PD. Therefore, these CSF biomarkers do not mirror disease progression, in particular progressive striatonigral degeneration as evaluated by clinical motor ratings (MDS-UPDRS III) and DaTscan measures. Whether these CSF biomarkers change over a longer time course, during more advanced stages of $\mathrm{PD}$, or in relation to, for example, blood-brain barrier changes, can be reassessed once further PPMI biomarker analyses are conducted.

CSF $\alpha$-syn assays measure the total physiologic protein rather than its select pathologic forms, and cellular events that lead to its release into extracellular CSF are not well-understood. The development of assays that measure other forms of $\alpha$-syn such as Pser129 $\alpha$-syn ${ }^{22}$ or $\alpha$-syn oligomers ${ }^{23,24}$ may provide stronger indices of disease activity. Although it is possible that decreased levels of CSF $\alpha$-syn in PD may normalize (increase) with effective neuroprotective therapy as target engagement, this will need to be tested in the setting of an effective intervention. CSF levels of $\mathrm{t}$-tau and p-tau181 levels have been extensively studied in $\mathrm{AD}$, where they are related to neuronal damage and neurofibrillary changes. They increase in the presymptomatic mild cognitive impairment stage, and remain stably elevated or even decrease slightly once the symptomatic phase with memory loss is present. ${ }^{25,26}$ It may therefore be important to similarly analyze people at risk for PD, such as asymptomatic mutation carriers and people with idiopathic nonmotor symptoms, such as RBD or hyposmia. ${ }^{27}$

Analyses of t-tau and p-tau proteins and $A \beta 42$ in longitudinal CSF samples in 403 drug-naive patients 


\begin{tabular}{|c|c|c|c|c|c|c|c|c|c|c|}
\hline \multirow[b]{3}{*}{ Variable } & \multicolumn{10}{|c|}{$\begin{array}{l}\text { Movement Disorder Society-sponsored revision of the Unified Parkinson's Disease Rating Scale (MDS-UPDRS), DaTscan levels, and CSF analytes ( } \beta \text {-amyloid 1-42 [A } \beta 42] \text {, total tau protein } \\
\text { t-tau], phosphorylated tau protein [p-tau], } \alpha \text {-synuclein [ } \alpha \text {-syn], and their ratios) at baseline and } 6 \text { and } 12 \text { months in patients with Parkinson disease (PD) and healthy controls (HC) }\end{array}$} \\
\hline & \multicolumn{5}{|c|}{ Patients with PD } & \multicolumn{5}{|l|}{$\mathrm{HC}$} \\
\hline & Baseline & $\begin{array}{l}\text { Change at } \\
6 \text { months }\end{array}$ & $\begin{array}{l}\text { Change at } \\
12 \text { months }\end{array}$ & $\begin{array}{l}p \text { Value (baseline } \\
\text { vs } 6 \text { months) }\end{array}$ & $\begin{array}{l}p \text { Value (baseline } \\
\text { vs } 12 \text { months) }\end{array}$ & Baseline & $\begin{array}{l}\text { Change at } \\
6 \text { months }\end{array}$ & $\begin{array}{l}\text { Change at } \\
12 \text { months }\end{array}$ & $\begin{array}{l}p \text { Value (baseline } \\
\text { vs } 6 \text { months) }\end{array}$ & $\begin{array}{l}p \text { Value (baseline } \\
\text { vs } 12 \text { months) }\end{array}$ \\
\hline MDS-UPDRS III & & & & $<0.0001$ & $<0.0001$ & & & & NA & 0.007 \\
\hline$n$ & 173 & 173 & 148 & & & 112 & NA & 112 & & \\
\hline Mean (SD) & 21.86 (8.6) & $3.41(6.0)$ & 4.46 (7.9) & & & $1.38(2.4)$ & & $0.53(2.0)$ & & \\
\hline Min, max & $20.6,23.2$ & $2.5,4.3$ & $3.2,5.7$ & & & $0.9,1.8$ & & $0.1,0.9$ & & \\
\hline Mean caudate & & & & NA & $<0.0001$ & & & & NA & NA \\
\hline$n$ & 172 & NA & 169 & & & 112 & NA & NA & & \\
\hline Mean (SD) & $1.99(0.549)$ & & $-0.22(0.27)$ & & & $2.98(0.63)$ & & & & \\
\hline Min, max & $1.90,2.07$ & & $-0.26,-0.18$ & & & $2.86,3.09$ & & & & \\
\hline Mean putamen & & & & NA & $<0.0001$ & & & & NA & NA \\
\hline$n$ & 172 & NA & 169 & & & 112 & NA & NA & & \\
\hline Mean (SD) & $0.79(0.28)$ & & $-0.11(0.15)$ & & & $2.09(0.55)$ & & & & \\
\hline Min, max & $0.75,0.84$ & & $-0.14,-0.10$ & & & $1.99,2.20$ & & & & \\
\hline Mean striatum & & & & NA & $<0.0001$ & & & & NA & NA \\
\hline$n$ & 172 & NA & 169 & & & 112 & NA & NA & & \\
\hline Mean (SD) & 1.39 (0.39) & & $-0.17(0.19)$ & & & $2.53(0.57)$ & & & & \\
\hline Min, max & $1.33,1.45$ & & $-0.20,-0.14$ & & & $2.43,2.64$ & & & & \\
\hline$A \beta 42$ & & & & 0.33 & 0.01 & & & & 0.09 & 0.002 \\
\hline$n$ & 173 & 173 & 173 & & & 112 & 112 & 112 & & \\
\hline Median & 361.10 & 7.50 & 11.50 & & & 378.15 & 6.15 & 21.35 & & \\
\hline Min, max & $139.9,670.0$ & $-242.2,205.0$ & $-207.1,316.8$ & & & $88.8,680.3$ & $-230.3,152.4$ & $-265.3,190.0$ & & \\
\hline t-tau & & & & 0.10 & 0.56 & & & & 0.81 & 0.30 \\
\hline$n$ & 171 & 171 & 170 & & & 110 & 110 & 110 & & \\
\hline Median & 38.70 & -1.20 & -0.15 & & & 44.65 & -0.25 & 0.70 & & \\
\hline Min, $\max$ & $15.6,121.0$ & $-15.4,21.8$ & $-28.4,36.7$ & & & $18.4,188.2$ & $-26.6,35.4$ & $-27.8,39.6$ & & \\
\hline p-tau & & & & 0.32 & 0.001 & & & & 0.19 & 0.15 \\
\hline$n$ & 173 & 173 & 172 & & & 112 & 112 & 112 & & \\
\hline Median & 11.40 & 0.20 & 1.95 & & & 14.00 & -0.35 & 0.55 & & \\
\hline Min, $\max$ & $4.7,39.7$ & $-21.7,40.3$ & $-26.5,46.6$ & & & $6.1,58.5$ & $-24.3,39.3$ & $-30.4,74.6$ & & \\
\hline
\end{tabular}




\begin{tabular}{|c|c|c|c|c|c|c|c|c|c|c|}
\hline Table 2 & ontinued & & & & & & & & & \\
\hline \multirow[b]{2}{*}{ Variable } & \multicolumn{5}{|l|}{ Patients with PD } & \multicolumn{5}{|l|}{$\mathrm{HC}$} \\
\hline & Baseline & $\begin{array}{l}\text { Change at } \\
6 \text { months }\end{array}$ & $\begin{array}{l}\text { Change at } \\
12 \text { months }\end{array}$ & $\begin{array}{l}\text { p Value (baseline } \\
\text { vs } 6 \text { months) }\end{array}$ & $\begin{array}{l}\text { p Value (baseline } \\
\text { vs } 12 \text { months) }\end{array}$ & Baseline & $\begin{array}{l}\text { Change at } \\
6 \text { months }\end{array}$ & $\begin{array}{l}\text { Change at } \\
12 \text { months }\end{array}$ & $\begin{array}{l}p \text { Value (baseline } \\
\text { vs } 6 \text { months) }\end{array}$ & $\begin{array}{l}p \text { Value (baseline } \\
\text { vs } 12 \text { months) }\end{array}$ \\
\hline$\alpha$-syn & & & & 0.43 & 0.79 & & & & 0.24 & 0.96 \\
\hline $\mathrm{n}$ & 173 & 172 & 173 & & & 112 & 112 & 112 & & \\
\hline Median & 1714.39 & 31.95 & 14.15 & & & 1950.13 & 8.81 & -5.00 & & \\
\hline Min, $\max$ & $332.93,6694.55$ & $-4503.15,1301.97$ & $-4602.02,1540.90$ & & & $592.56,5237.68$ & $-1912.52,2258.43$ & $-2292.36,1748.10$ & & \\
\hline$\alpha$-syn ${ }^{a}$ & & & & 0.84 & 0.99 & & & & 0.77 & 0.55 \\
\hline $\mathrm{n}$ & 82 & 81 & 82 & & & 43 & 43 & 43 & & \\
\hline Median & 1712.71 & 33.74 & 55.01 & & & 1941.14 & 5.26 & -101.64 & & \\
\hline Min, max & $581.17,5110.77$ & $-2239.79,837.42$ & $-2107.86,1284.25$ & & & $683.94,5237.68$ & $-1912.52,1164.75$ & $-2292.36,1529.98$ & & \\
\hline p-tau/t-tau & & & & 0.34 & 0.002 & & & & 0.39 & 0.43 \\
\hline $\mathrm{n}$ & 171 & 171 & 169 & & & 110 & 110 & 110 & & \\
\hline Median & 0.297 & 0.014 & 0.044 & & & 0.29 & -0.01 & 0.02 & & \\
\hline Min, max & $0.150,0.883$ & $-0.659,1.006$ & $-0.607,2.127$ & & & $0.13,0.79$ & $-0.51,0.44$ & $-0.54,1.37$ & & \\
\hline $\mathrm{t}$-tau/A $\beta 42$ & & & & 0.007 & 0.003 & & & & 0.80 & 0.57 \\
\hline $\mathrm{n}$ & 171 & 171 & 170 & & & 110 & 110 & 110 & & \\
\hline Median & 0.11 & -0.01 & -0.01 & & & 0.111 & -0.002 & -0.003 & & \\
\hline Min, max & $0.06,0.53$ & $-0.06,0.24$ & $-0.15,0.27$ & & & $0.071,2.12$ & $-0.278,0.08$ & $-0.199,0.15$ & & \\
\hline p-tau/Aß42 & & & & 0.42 & 0.01 & & & & 0.04 & 0.73 \\
\hline $\mathrm{n}$ & 173 & 173 & 172 & & & 112 & 112 & 112 & & \\
\hline Median & 0.03 & 0.00 & 0.01 & & & 0.04 & -0.00 & 0.00 & & \\
\hline Min, max & $0.01,0.17$ & $-0.07,0.09$ & $-0.08,0.23$ & & & $0.02,0.66$ & $-0.23,0.07$ & $-0.19,0.39$ & & \\
\hline t-tau/ $\alpha$-syn & & & & 0.09 & 0.61 & & & & 0.32 & 0.47 \\
\hline$n$ & 171 & 170 & 170 & & & 110 & 110 & 110 & & \\
\hline Median & 0.02 & -0.001 & -0.001 & & & 0.02 & -0.001 & 0.00 & & \\
\hline$n$ & 82 & 81 & 81 & & & 43 & 43 & 43 & & \\
\hline Median & 0.02 & -0.00 & -0.00 & & & 0.024 & -0.001 & 0.000 & & \\
\hline Min, max & $0.01,0.05$ & $-0.03,0.02$ & $-0.02,0.02$ & & & $0.01,0.06$ & $-0.03,0.01$ & $-0.03,0.02$ & & \\
\hline
\end{tabular}

Abbreviation: NA = not applicable.

$p$ Values are based on the ranks of the biological variables. DaTscan is not performed at 6 months in patients with PD, and is performed only at baseline in HC.

a Subset of participants with hemoglobin $<200 \mathrm{ng} / \mathrm{mL}$ at all time points, excluding those with missing hemoglobin values at one or more time points. 


\begin{tabular}{|c|c|c|c|c|c|c|c|}
\hline \multirow[b]{3}{*}{ Variables } & \multicolumn{7}{|c|}{$\begin{array}{l}\text { Comparison over time in patients with Parkinson disease (PD) vs healthy controls (HC) of CSF levels of } \beta \text {-amyloid 1-42 (A } \beta 42) \text {, total } \\
\text { tau protein (t-tau), phosphorylated tau protein (p-tau), and } \alpha \text {-synuclein }(\alpha \text {-syn) }\end{array}$} \\
\hline & \multicolumn{3}{|l|}{ Patients with PD } & \multicolumn{3}{|l|}{$\mathrm{HC}$} & \multirow{2}{*}{$\begin{array}{l}\text { p Value } \\
\text { (PD vs HC }\end{array}$} \\
\hline & Baseline & 6 months & 12 months & Baseline & 6 months & 12 months & \\
\hline $\mathrm{A} \beta 42$ & & & & & & & 0.134 \\
\hline $\mathrm{n}$ & 173 & 173 & 173 & 112 & 112 & 112 & \\
\hline Median & 361.10 & 361.70 & 375.50 & 378.15 & 373.80 & 396.80 & \\
\hline Min, $\max$ & $139.90,670.00$ & $129.30,687.00$ & $144.10,732.50$ & $88.80,680.30$ & $98.00,609.80$ & $95.20,691.30$ & \\
\hline t-tau & & & & & & & 0.0004 \\
\hline $\mathrm{n}$ & 171 & 173 & 172 & 110 & 112 & 112 & \\
\hline Median & 38.70 & 37.40 & 39.05 & 44.65 & 44.75 & 45.15 & \\
\hline Min, max & $15.60,121.00$ & $15.60,134.70$ & $16.60,128.80$ & $18.40,188.20$ & $16.80,180.50$ & $19.40,216.20$ & \\
\hline p-tau & & & & & & & 0.006 \\
\hline $\mathrm{n}$ & 173 & 173 & 172 & 112 & 112 & 112 & \\
\hline Median & 11.40 & 11.50 & 14.10 & 14.00 & 13.30 & 15.75 & \\
\hline Min, max & $4.70,39.70$ & $5.10,56.30$ & $5.40,61.80$ & $6.10,58.50$ & $6.00,52.50$ & $6.00,89.50$ & \\
\hline$\alpha$-syn & & & & & & & 0.002 \\
\hline $\mathrm{n}$ & 173 & 172 & 173 & 112 & 112 & 112 & \\
\hline Median & 1714.39 & 1779.73 & 1720.77 & 1950.13 & 2069.87 & 2036.88 & \\
\hline Min, max & $332.93,6694.55$ & $472.92,4659.05$ & $352.36,5157.08$ & $592.56,5237.68$ & $658.61,5208.86$ & $729.32,5295.43$ & \\
\hline$\alpha$-syn $^{a}$ & & & & & & & 0.109 \\
\hline $\mathrm{n}$ & 82 & 81 & 82 & 43 & 43 & 43 & \\
\hline Median & 1712.71 & 1802.91 & 1816.15 & 1941.14 & 1981.53 & 2018.74 & \\
\hline Min, $\max$ & $581.17,5110.77$ & $707.06,4264.73$ & $797.87,5157.08$ & $683.94,5237.68$ & $890.57,5157.39$ & $729.32,4784.16$ & \\
\hline p-tau/t-tau & & & & & & & 0.215 \\
\hline $\mathrm{n}$ & 171 & 173 & 171 & 110 & 112 & 112 & \\
\hline Median & 0.30 & 0.29 & 0.340 & 0.29 & 0.27 & 0.31 & \\
\hline Min, $\max$ & $0.15,0.88$ & $0.13,1.29$ & $0.07,2.48$ & $0.13,0.79$ & $0.14,0.95$ & $0.14,1.58$ & \\
\hline $\mathrm{t}$-tau/A $\beta 42$ & & & & & & & 0.002 \\
\hline $\mathrm{n}$ & 171 & 173 & 172 & 110 & 112 & 112 & \\
\hline Median & 0.11 & 0.10 & 0.10 & 0.111 & 0.115 & 0.112 & \\
\hline Min, $\max$ & $0.06,0.53$ & $0.06,0.48$ & $0.06,0.51$ & $0.071,2.12$ & $0.07,1.84$ & $0.06,2.27$ & \\
\hline p-tau/Aß42 & & & & & & & 0.085 \\
\hline $\mathrm{n}$ & 173 & 173 & 172 & 112 & 112 & 112 & \\
\hline Median & 0.03 & 0.03 & 0.04 & 0.04 & 0.03 & 0.04 & \\
\hline Min, $\max$ & $0.01,0.17$ & $0.01,0.14$ & $0.01,0.28$ & $0.02,0.66$ & $0.02,0.43$ & $0.02,0.50$ & \\
\hline t-tau/ $\alpha$-syn & & & & & & & 0.202 \\
\hline $\mathbf{n}$ & 171 & 172 & 172 & 110 & 112 & 112 & \\
\hline Median & 0.02 & 0.02 & 0.02 & 0.02 & 0.02 & 0.02 & \\
\hline Min, $\max$ & $0.01,0.07$ & $0.01,0.05$ & $0.01,0.06$ & $0.01,0.06$ & $0.01,0.05$ & $0.01,0.05$ & \\
\hline t-tau/ $\alpha-\operatorname{syn}^{a}$ & & & & & & & 0.515 \\
\hline $\mathrm{n}$ & 82 & 81 & 81 & 43 & 43 & 43 & \\
\hline Median & 0.02 & 0.02 & 0.02 & 0.02 & 0.02 & 0.02 & \\
\hline Min, $\max$ & $0.01,0.05$ & $0.01,0.05$ & $0.01,0.06$ & $0.01,0.06$ & $0.02,0.05$ & $0.01,0.05$ & \\
\hline
\end{tabular}

$p$ Values are based on the ranks of the biologic variables.

a Subset of participants with hemoglobin $<200 \mathrm{ng} / \mathrm{mL}$ at all time points; excludes those missing hemoglobin values at one or more time points. 


\begin{abstract}
Table 4 Correlation between change in CSF biomarkers and change in the Movement Disorder Society-sponsored revision of the Unified Parkinson's Disease Rating Scale (MDS-UPDRS) part III motor score and the total score in patients with Parkinson disease (PD) and healthy controls $(\mathrm{HC})$
\end{abstract}

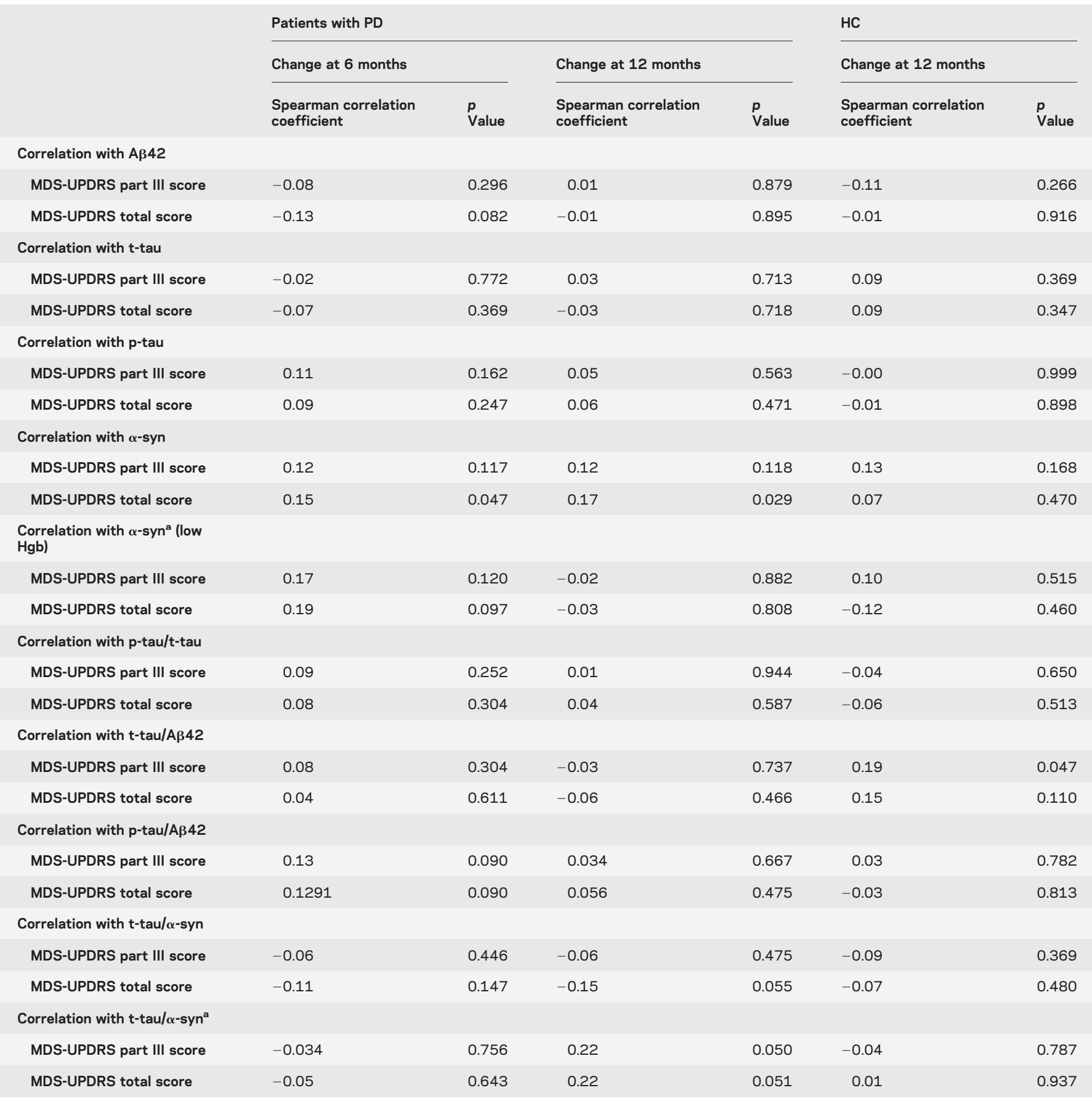

Abbreviations: $\alpha$-syn $=\alpha$-synuclein; A $\beta 42=\beta$-amyloid 1-42; $\mathrm{p}$-tau $=$ phosphorylated tau protein; $\mathrm{Hgb}=$ hemoglobin; $\mathrm{t}$-tau $=$ total tau protein.

Controls did not complete MDS-UPDRS at 6 months.

a Subset of participants with $\mathrm{Hgb}<200 \mathrm{ng} / \mathrm{mL}$ at all time points; excludes those missing $\mathrm{Hgb}$ values at one or more time points.

with PD at enrollment in the Deprenyl and Tocopherol Antioxidative Therapy of PD (DATATOP) placebo-controlled clinical trial revealed a slight but significant positive correlation between the rate of change in $\mathrm{t}$-tau or $\mathrm{t}$-tau/A $\beta 42$ levels and changes in Unified Parkinson's Disease Rating Scale scores. ${ }^{13}$ In the PPMI cohort, the correlation between clinical progression by total MDS-UPDRS scores and changes of CSF $\alpha$-syn after 6 and 12 months of observation supports a pathophysiologic connection of CSF $\alpha$-syn levels with motor progression, albeit weak. However, this is not directly related to measures of presynaptic dopamine integrity in the basal ganglia by DaTscan.

Since the PD phenotype is very heterogeneous, different subtypes could show different biomarker 
Table 5 Longitudinal relationship between CSF biomarkers and Parkinson disease (PD) medications in patients with PD (calculated as levodopa equivalent dosages [LED] as published ${ }^{19}$ )

\begin{tabular}{|c|c|c|}
\hline \multirow[b]{2}{*}{ Variable } & \multicolumn{2}{|l|}{ Patients with PD } \\
\hline & Estimate $(95 \% \mathrm{Cl})$ & $p$ Value \\
\hline \multicolumn{3}{|l|}{ Relationship with Aß42 } \\
\hline PD medication use & $-4.07(-29.38$ to 21.24$)$ & 0.750 \\
\hline Total LED & $0.08(-0.01$ to 0.16$)$ & 0.074 \\
\hline LED subtotal-dopamine replacement & $0.08(-0.02$ to 0.18$)$ & 0.114 \\
\hline LED subtotal-dopamine agonists & $-0.00(-0.18$ to 0.18$)$ & 0.969 \\
\hline \multicolumn{3}{|l|}{ Relationship with $\mathrm{t}$-tau } \\
\hline PD medication use & 5.76 (-8.81 to 20.33$)$ & 0.434 \\
\hline Total LED & $0.03(-0.01$ to 0.08$)$ & 0.164 \\
\hline LED subtotal-dopamine replacement & $0.03(-0.03$ to 0.09$)$ & 0.315 \\
\hline LED subtotal-dopamine agonists & $0.04(-0.06$ to 0.14$)$ & 0.400 \\
\hline \multicolumn{3}{|l|}{ Relationship with p-tau } \\
\hline PD medication use & $-12.31(-49.38$ to 24.76$)$ & 0.510 \\
\hline Total LED & $0.06(-0.07$ to 0.18$)$ & 0.365 \\
\hline LED subtotal-dopamine replacement & $0.02(-0.13$ to 0.17$)$ & 0.808 \\
\hline LED subtotal-dopamine agonists & $0.13(-0.14$ to 0.39$)$ & 0.340 \\
\hline \multicolumn{3}{|l|}{ Relationship with $\alpha$-syn } \\
\hline PD medication use & $-28.54(-48.40$ to -8.69$)$ & 0.005 \\
\hline Total LED & $-0.06(-0.12$ to 0.01$)$ & 0.073 \\
\hline LED subtotal-dopamine replacement & $0.02(-0.06$ to 0.10$)$ & 0.560 \\
\hline LED subtotal-dopamine agonists & $-0.28(-0.41$ to -0.14$)$ & $<0.0001$ \\
\hline \multicolumn{3}{|l|}{ Relationship with $\alpha$-syn ${ }^{a}$} \\
\hline PD medication use & $-43.24(-71.34$ to -15.15$)$ & 0.004 \\
\hline Total LED & $-0.09(-0.19$ to 0.01$)$ & 0.077 \\
\hline LED subtotal-dopamine replacement & $0.07(-0.05$ to 0.19$)$ & 0.260 \\
\hline LED subtotal-dopamine agonists & $-0.42(-0.59$ to -0.25$)$ & $<0.0001$ \\
\hline \multicolumn{3}{|l|}{ Relationship with p-tau/t-tau } \\
\hline PD medication use & $-7.10(-45.86$ to 31.65$)$ & 0.716 \\
\hline Total LED & $0.05(-0.08$ to 0.18$)$ & 0.407 \\
\hline LED subtotal-dopamine replacement & $-0.01(-0.17$ to 0.14$)$ & 0.878 \\
\hline LED subtotal-dopamine agonists & $0.13(-0.15$ to 0.40$)$ & 0.373 \\
\hline \multicolumn{3}{|l|}{ Relationship with $\mathrm{t}$-tau/A $\beta 42$} \\
\hline PD medication use & $9.59(-17.64$ to 36.81$)$ & 0.485 \\
\hline Total LED & $-0.01(-0.10$ to 0.08$)$ & 0.803 \\
\hline LED subtotal-dopamine replacement & $-0.01(-0.12$ to 0.10$)$ & 0.862 \\
\hline LED subtotal-dopamine agonists & $0.04(-0.15$ to 0.23$)$ & 0.682 \\
\hline \multicolumn{3}{|l|}{ Relationship with $p$-tau/Aß42 } \\
\hline PD medication use & $-11.09(-47.81$ to 25.62$)$ & 0.549 \\
\hline Total LED & $0.04(-0.09$ to 0.16$)$ & 0.565 \\
\hline LED subtotal-dopamine replacement & $-0.01(-0.16$ to 0.14$)$ & 0.891 \\
\hline LED subtotal-dopamine agonists & $0.17(-0.09$ to 0.42$)$ & 0.212 \\
\hline \multicolumn{3}{|l|}{ Relationship with t-tau/ $\alpha$-syn } \\
\hline PD medication use & 39.36 (8.42 to 70.29$)$ & 0.013 \\
\hline
\end{tabular}

Continued dynamics. We found an increased $t$-tau/A $\beta 42$ ratio in participants with RBD, which may be part of a clinical subtype of PD with faster progression ${ }^{28}$ and has been associated with greater synuclein pathology in PD. ${ }^{29}$ Other clinical subtypes need to be determined upon longer clinical follow-up.

Levels of $A \beta 42$ and $p$-tau showed a small mean increase over 12 months in $\mathrm{PD}$, and this was not associated with the $A P O E \& 4$ allele or with cognition (other than visuospatial deficits). Levels of CSF A 342 were generally above the cutoff developed in the Alzheimer's Disease Neuroimaging Initiative study (quantified by the same assay) of $192 \mathrm{pg} / \mathrm{mL}$ that has been validated against autopsy and against amyloid PET imaging. ${ }^{30}$ Given the relatively young age (mean age 60.9 years) and early, de novo status of the PPMI PD cohort, it is likely that most participants do not yet have important coexisting amyloid plaque pathology. Among participants in PPMI, those with lower CSF $A \beta 42$ at baseline have been shown to have greater risk of cognitive decline over 2 years. ${ }^{31}$

The potentially confounding effect of pharmacotherapy on biomarkers, especially $\alpha$-syn, has not been investigated intensively. In PPMI, the first lumbar puncture was performed with all patients drugnaive, but with progressing motor symptoms, participants started dopaminergic treatment. The question of an effect of dopaminergic treatment on biomarker measurement has been raised previously ${ }^{32}$ as D1, D2, D4, and D5 receptors are expressed in the choroid plexus, which, upon activation, could alter CSF homeostasis. ${ }^{33}$ Some dopamine agonists decrease $\alpha$-syn phosphorylation ${ }^{34}$ and may protect against neuroinflammation ${ }^{35}$ and may thus have neuroprotective properties. In fact, we found that patients using PD medications had greater changes in CSF $\alpha$-syn, especially those on dopamine agonists. Whether the effect on CSF $\alpha$-syn changes reflects these interactions and whether there are different binding properties of dopamine agonists will require further study.

Our focus was on 4 known core markers of neurodegeneration relevant to PD (i.e., $\alpha$-syn, $A \beta 42$, t-tau, and p-tau) with well-validated assays for their quantification in CSF. Similar to AD, it is highly likely that a panel of multiple biomarkers will be helpful to mirror the complex process of progressive neurodegeneration in PD. Additional PD biomarker candidates have been proposed based mainly on cross-sectional studies and may be candidates for longitudinal analysis; for example, phosphorylated ${ }^{22}$ and oligomeric $\alpha$-syn, ${ }^{23,36}$ neurofilament light chains, ${ }^{11}$ and others. In addition, there is a need to identify new biomarker candidates that may predict or track clinical progression in PD, either hypothesis-driven by the increasing knowledge of the pathologic 


\begin{tabular}{|c|c|c|}
\hline Continued & & \\
\hline \multirow[b]{2}{*}{ Variable } & \multicolumn{2}{|l|}{ Patients with PD } \\
\hline & Estimate $(95 \% \mathrm{Cl})$ & $p$ Value \\
\hline Total LED & $0.10(-0.00$ to 0.20$)$ & 0.061 \\
\hline LED subtotal-dopamine replacement & $-0.00(-0.13$ to 0.12$)$ & 0.991 \\
\hline LED subtotal-dopamine agonists & 0.36 (0.14 to 0.58$)$ & 0.001 \\
\hline \multicolumn{3}{|l|}{ Relationship with t-tau/ $\alpha$-syn ${ }^{a}$} \\
\hline PD medication use & $68.10(24.76$ to 111.44$)$ & 0.003 \\
\hline Total LED & 0.16 (0.01 to 0.32$)$ & 0.044 \\
\hline LED subtotal-dopamine replacement & $-0.08(-0.27$ to 0.11$)$ & 0.400 \\
\hline LED subtotal-dopamine agonists & 0.67 (0.41 to 0.94$)$ & $<0.0001$ \\
\hline
\end{tabular}

Abbreviations: $\alpha$-syn $=\alpha$-synuclein; $\mathrm{A} \beta 42=\beta$-amyloid; $\mathrm{Cl}=$ confidence interval; $\mathrm{p}$-tau $=$ phosphorylated tau; $\mathrm{t}$-tau $=$ total tau.

$p$ Values are based on the ranks of the biologic variables.

a Subset of participants with hemoglobin $<200 \mathrm{ng} / \mathrm{mL}$ at all time points; excludes those missing hemoglobin values at one or more time points.

processes or unbiased with continuously improving sensitive (e.g., -omics) technology. Although we did not find evidence for significant progression of the CSF biomarkers we studied during 12 months early in the course of PD, longer follow-up and expansion of these and other CSF biomarker panels in the PPMI and other cohorts will help to define a more detailed picture of biochemical events in the brain along the course of PD.

\section{AUTHOR CONTRIBUTIONS}

B.M., D.G., and C.S.C. designed the study and were responsible for data processing. C.J.C.-G. and C.S.C. oversaw all statistical analyses. P.T., L.M.S., J.Q.T., and A.S. were involved in sample analyses and data interpretation. M.F. and K.M. oversaw patient recruitment and assisted in the interpretation of data. B.M., C.J.C.-G., and D.G. wrote the manuscript. C.S.C., P.T., L.M.S., J.Q.T., A.S., M.F., and K.M. coedited the manuscript. B.M., D.G., and K.M. had full access to the clinical primary data. All authors had access to the data generated in the study including the statistical analysis and decided to submit the paper for publication.

\section{ACKNOWLEDGMENT}

The authors thank the Michael J. Fox Foundation, their PPMI colleagues, and the individuals who participated in this study.

\section{STUDY FUNDING}

PPMI is sponsored by the Michael J. Fox Foundation for Parkinson's Research (MJFF) and is cofunded by MJFF, AbbVie, Avid Radiopharmaceuticals, Biogen Idec, Bristol-Myers Squibb, Covance, Eli Lilly \& Co., F. Hoffman-La Roche, Ltd., GE Healthcare, Genentech, GlaxoSmithKline, Lundbeck, Merck, MesoScale, Piramal, Pfizer, and UCB. This study is funded by The MJFF and funding partners, including Abbott, Biogen Idec, F. Hoffman-La Roche Ltd., GE Healthcare, Genentech, and Pfizer Inc. J.Q.T. is supported in part by P50 NS053488.

\section{DISCLOSURE}

B. Mollenhauer has received independent research grants from TEVAPharma, Desitin, Boehringer Ingelheim, and GE Healthcare; honoraria for consultancy from Bayer Schering Pharma AG, Roche, AbbVie, TEVA-Pharma, and Biogen, and for presentations from GlaxoSmithKline, Orion Pharma, and TEVA-Pharma; and travel costs from TEVAPharma. B.M. is a member of the executive steering committee of the Parkinson's Progression Marker Initiative and the Systemic Synuclein
Sampling Study of the Michael J. Fox Foundation for Parkinson's Research (MJFF); has received grants from the BMBF, EU, Parkinson Fonds Deutschland, Deutsche Parkinson Vereinigung, MJFF, and Stifterverband für die deutsche Wissenschaft; and has scientific collaborations with Roche, Bristol Myers Squibb, Ely Lilly, Covance, and Biogen. C. Caspell-Garcia served as a consultant receiving fees from MJFF; and received research funding from The Michael J. Fox Foundation for Parkinson's Research. C. Coffey served as a consultant receiving fees from MJFF; and received research funding from NINDS, NHLBI, and MJFF. P. Taylor is an employee of BioLegend. L. Shaw receives funding from the NIH/NIA, U19 AG024904; from MJFF, Eli Lilly, and Roche; honoraria for consultancy from Novartis and Eli Lilly; and travel expenses from Eli Lilly and Roche and honorarium from Eli Lilly and Novartis; and has provided QC oversight for immunoassays produced by Fujirebio and Roche as part of the ADNI and PPMI studies. J. Trojanowski may accrue revenue in the future on patents submitted by the University of Pennsylvania wherein he is coinventor and received revenue from the sale of Avid to Eli Lily as coinventor on imaging-related patents submitted by the University of Pennsylvania; and receives research support from the NIH, GSK, Janssen, Biogen, and several nonprofits. A. Singleton was supported by grant Z01AG000949-06 from the Intramural Research Program, National Institute on Aging, NIH. Ju-Hee was supported by grant MRC 2014009392 from the National Research Foundation of Korea, Ministry of Science, ICT, and Future Planning. M. Frasier is an employee of MJFF. K. Marek is a consultant for Pfizer, GE Healthcare, Merck, Lilly, BMS, Piramal, Prothena, Neurophage, nLife, and Roche; receives funding for the following grants: W81XWH-06-10678, Establishing an 'at risk' cohort for Parkinson Disease Neuroprevention using olfactory testing and DAT imaging, DOD, Investigator 10/ 1/06-09/30/15; Parkinson's Progression Marker Initiative, Michael J. Fox Foundation, Principal Investigator 6/15/09-6/14/18; DAT imaging in LRRK2 family members, the Michael J. Fox Foundation, Principal Investigator $1 / 15 / 10-1 / 14 / 15$; and has ownership in Molecular NeuroImaging, LLC. D. Galasko is supported by NIH grant AGO5131 and by the Michael J. Fox Foundation; and has provided consultation for vTv Pharmaceuticals, Eli Lilly, Inc., and Proclara, Inc. Go to Neurology.org for full disclosures.

Received February 12, 2017. Accepted in final form August 24, 2017.

\section{REFERENCES}

1. Klein C, Westenberger A. Genetics of Parkinson's disease. Cold Spring Harb Perspect Med 2012;2:a008888.

2. Brettschneider J, Del Tredici K, Lee VM, Trojanowski JQ. Spreading of pathology in neurodegenerative diseases: a focus on human studies. Nat Rev Neurosci 2015;16: 109-120.

3. Fagan AM, Mintun MA, Mach RH, et al. Inverse relation between in vivo amyloid imaging load and cerebrospinal fluid Abeta42 in humans. Ann Neurol 2006;59:512-519.

4. Tapiola T, Overmyer M, Lehtovirta M, et al. The level of cerebrospinal fluid tau correlates with neurofibrillary tangles in Alzheimer's disease. Neuroreport 1997;8:3961-3963.

5. Tokuda T, Salem SA, Allsop D, et al. Decreased alphasynuclein in cerebrospinal fluid of aged individuals and subjects with Parkinson's disease. Biochem Biophys Res Commun 2006;349:162-166.

6. Mollenhauer B, Locascio JJ, Schulz-Schaeffer W, SixelDoring F, Trenkwalder C, Schlossmacher MG. AlphaSynuclein and tau concentrations in cerebrospinal fluid of patients presenting with parkinsonism: a cohort study. Lancet Neurol 2011;10:230-240.

7. Hong Z, Shi M, Chung KA, et al. DJ-1 and alphasynuclein in human cerebrospinal fluid as biomarkers of Parkinson's disease. Brain 2010;133:713-726.

8. Kang JH, Irwin DJ, Chen-Plotkin AS, et al. Association of cerebrospinal fluid beta-amyloid 1-42, T-tau, P-tau181, and alpha-synuclein levels with clinical features of drug- 
naive patients with early Parkinson disease. JAMA Neurol 2013;70:1277-1287.

9. Kang JH, Mollenhauer B, Coffey CS, et al. CSF biomarkers associated with disease heterogeneity in early Parkinson's disease: the Parkinson's Progression Markers Initiative study. Acta Neuropathol 2016;131:935-949.

10. Majbour NK, Vaikath NN, Eusebi P, et al. Longitudinal changes in CSF alpha-synuclein species reflect Parkinson's disease progression. Mov Disord 2016;31:1535-1542.

11. Hall S, Ohrfelt A, Constantinescu R, et al. Accuracy of a panel of 5 cerebrospinal fluid biomarkers in the differential diagnosis of patients with dementia and/or Parkinsonian disorders. Arch Neurol 2012;69:1445-1452.

12. Stewart T, Liu C, Ginghina C, et al. Cerebrospinal fluid alpha-synuclein predicts cognitive decline in Parkinson disease progression in the DATATOP cohort. Am J Pathol 2014;184:966-975.

13. Zhang J, Mattison HA, Liu C, et al. Longitudinal assessment of tau and amyloid beta in cerebrospinal fluid of Parkinson disease. Acta Neuropathol 2013;126:671-682.

14. Mollenhauer B, Zimmermann J, Sixel-Doring F, et al. Monitoring of 30 marker candidates in early Parkinson disease as progression markers. Neurology 2016;87:168-177.

15. Gomperts SN, Locascio JJ, Makaretz SJ, et al. Tau positron emission tomographic imaging in the Lewy body diseases. JAMA Neurol 2016;73:1334-1341.

16. Irwin DJ, Grossman M, Weintraub D, et al. Neuropathological and genetic correlates of survival and dementia onset in synucleinopathies: a retrospective analysis. Lancet Neurol 2017;16:55-65.

17. The Parkinson Progression Marker Initiative (PPMI). Prog Neurobiol 2011;95:629-635.

18. Goetz CG, Tilley BC, Shaftman SR, et al. Movement Disorder Society-sponsored revision of the Unified Parkinson's Disease Rating Scale (MDS-UPDRS): scale presentation and clinimetric testing results. Mov Disord 2008;23:2129-2170.

19. Tomlinson CL, Stowe R, Patel S, Rick C, Gray R, Clarke CE. Systematic review of levodopa dose equivalency reporting in Parkinson's disease. Mov Disord 2010;25:2649-2653.

20. Stiasny-Kolster K, Mayer G, Schafer S, Moller JC, HeinzelGutenbrunner M, Oertel WH. The REM sleep behavior disorder screening questionnaire: a new diagnostic instrument. Mov Disord 2007;22:2386-2393.

21. Nalls MA, Keller MF, Hernandez DG, et al. Baseline genetic associations in the Parkinson's Progression Markers Initiative (PPMI). Mov Disord 2016;31:79-85.

22. Wang Y, Shi M, Chung KA, et al. Phosphorylated alphasynuclein in Parkinson's disease. Sci Transl Med 2012;4: 121 ra120.

23. Hansson O, Hall S, Ohrfelt A, et al. Levels of cerebrospinal fluid alpha-synuclein oligomers are increased in
Parkinson's disease with dementia and dementia with Lewy bodies compared to Alzheimer's disease. Alzheimers Res Ther 2014;6:25.

24. Shahnawaz M, Tokuda T, Waragai M, et al. Development of a biochemical diagnosis of Parkinson disease by detection of alpha-synuclein misfolded aggregates in cerebrospinal fluid. JAMA Neurol 2017;74:163-172.

25. Fagan AM, Xiong C, Jasielec MS, et al. Longitudinal change in CSF biomarkers in autosomal-dominant Alzheimer's disease. Sci Transl Med 2014;6:226ra230.

26. Bateman RJ, Xiong C, Benzinger TL, et al. Clinical and biomarker changes in dominantly inherited Alzheimer's disease. N Engl J Med 2012;367:795-804.

27. Schrag A, Horsfall L, Walters K, Noyce A, Petersen I. Prediagnostic presentations of Parkinson's disease in primary care: a case-control study. Lancet Neurol 2015;14: 57-64.

28. Fereshtehnejad SM, Romenets SR, Anang JB, Latreille V, Gagnon JF, Postuma RB. New clinical subtypes of Parkinson disease and their longitudinal progression: a prospective cohort comparison with other phenotypes. JAMA Neurol 2015;72:863-873.

29. Vendette M, Gagnon JF, Decary A, et al. REM sleep behavior disorder predicts cognitive impairment in Parkinson disease without dementia. Neurology 2007;69:18431849.

30. Toledo JB, Vanderstichele H, Figurski M, et al. Factors affecting Abeta plasma levels and their utility as biomarkers in ADNI. Acta Neuropathol 2011;122:401-413.

31. Schrag A, Siddiqui UF, Anastasiou Z, Weintraub D, Schott JM. Clinical variables and biomarkers in prediction of cognitive impairment in patients with newly diagnosed Parkinson's disease: a cohort study. Lancet Neurol 2017; 16:66-75.

32. Mollenhauer B, Cullen V, Kahn I, et al. Direct quantification of CSF alpha-synuclein by ELISA and first crosssectional study in patients with neurodegeneration. Exp Neurol 2008;213:315-325.

33. Mignini F, Bronzetti E, Felici L, et al. Dopamine receptor immunohistochemistry in the rat choroid plexus. J Auton Pharmacol 2000;20:325-332.

34. Chau KY, Cooper JM, Schapira AH. Pramipexole reduces phosphorylation of alpha-synuclein at serine-129. J Mol Neurosci 2013;51:573-580.

35. Yu X, Yao JY, He J, Tian JW. Protection of MPTPinduced neuroinflammation and neurodegeneration by rotigotine-loaded microspheres. Life Sci 2015;124: 136-143.

36. Tokuda T, Qureshi MM, Ardah MT, et al. Detection of elevated levels of \{alpha\}-synuclein oligomers in CSF from patients with Parkinson disease. Neurology 2010;75: 1766-1772. 


\section{Neurology}

\section{Longitudinal CSF biomarkers in patients with early Parkinson disease and healthy controls \\ Brit Mollenhauer, Chelsea J. Caspell-Garcia, Christopher S. Coffey, et al. Neurology 2017;89;1959-1969 Published Online before print October 13, 2017 \\ DOI 10.1212/WNL.0000000000004609}

This information is current as of October 13, 2017

Neurology ${ }^{\circledR}$ is the official journal of the American Academy of Neurology. Published continuously since 1951, it is now a weekly with 48 issues per year. Copyright Copyright $@ 2017$ The Author(s). Published by Wolters Kluwer Health, Inc. on behalf of the American Academy of Neurology.. All rights reserved. Print ISSN: 0028-3878. Online ISSN: 1526-632X.

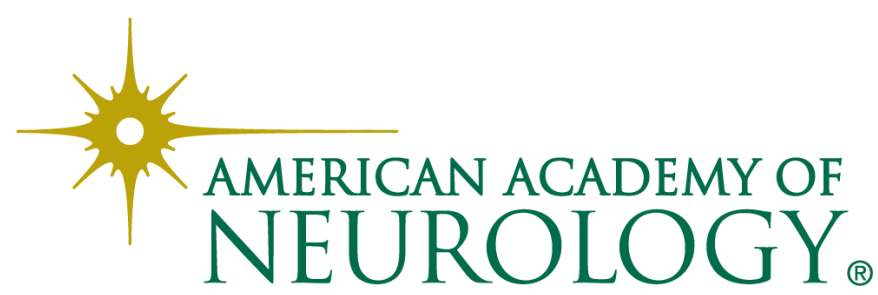




\section{Updated Information \& Services}

\section{Supplementary Material}

\section{References}

\section{Citations}

Subspecialty Collections

Permissions \& Licensing

\section{Reprints}

including high resolution figures, can be found at: http://n.neurology.org/content/89/19/1959.full

Supplementary material can be found at: http://n.neurology.org/content/suppl/2017/10/16/WNL.0000000000004 609.DC1

http://n.neurology.org/content/suppl/2017/10/16/WNL.0000000000004 609.DC2

http://n.neurology.org/content/suppl/2018/11/02/WNL.0000000000004 609.DC3

This article cites 36 articles, 4 of which you can access for free at: http://n.neurology.org/content/89/19/1959.full\#ref-list-1

This article has been cited by 4 HighWire-hosted articles: http://n.neurology.org/content/89/19/1959.full\#\#otherarticles

This article, along with others on similar topics, appears in the following collection(s):

\section{Cohort studies}

http://n.neurology.org/cgi/collection/cohort_studies

\section{Outcome research}

http://n.neurology.org/cgi/collection/outcome_research

Parkinson's disease/Parkinsonism

http://n.neurology.org/cgi/collection/parkinsons_disease_parkinsonism

Information about reproducing this article in parts (figures,tables) or in its entirety can be found online at:

http://www.neurology.org/about/about_the_journal\#permissions

Information about ordering reprints can be found online:

http://n.neurology.org/subscribers/advertise

Neurology ${ }^{\circledR}$ is the official journal of the American Academy of Neurology. Published continuously since 1951, it is now a weekly with 48 issues per year. Copyright Copyright ( 2017 The Author(s). Published by Wolters Kluwer Health, Inc. on behalf of the American Academy of Neurology.. All rights reserved. Print ISSN: 0028-3878. Online ISSN: 1526-632X.

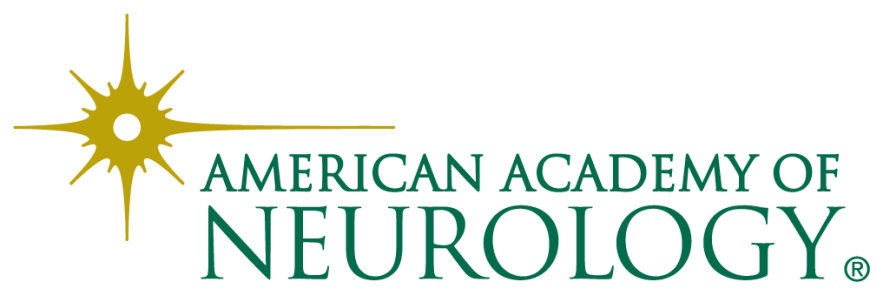

